\title{
SIETE DE SEPTIEMBRE
}

Susana Patiño*

¿6ómo se dirá mi nombre en inglés?

Tengo miedo de no entender cuando me llamen por el altavoz" Con sus tacones blancos, sus medias y su falda verde, parece que Eloísa Gómez viene de una boda y no del vuelo Delta 366 MEX-ATL. Nuestros pasaportes y visas están en un sobre de plástico con la orilla amarilla. Tal vez no sea tan grave lo que nos espera, porque también hay sobres aún más intimidantes con orillas rojas; pero Eloísa no piensa en claves cromáticas para adivinar el futuro, ella va segura de que éste es el tránsito normal en cualquier viaje: cruza sonriente la puerta corrediza de la pecera gigante donde hay que esperar el siguiente interrogatorio de la policía. Lleva su monedero apretado contra el pecho con las dos manos; intercambiamos la mirada de quien no necesita palabras para saber que hablamos el mismo idioma y me pregunta: “Aquí es dónde nos van a entregar las maletas, ¿verdad?” Eloísa me cuenta que pasó por una especie de caja del supermercado y que le embarraron los dedos sobre una pantalla de luz verde. "Híjole, entonces ¿tengo problemas con mis papeles? No sabía, sólo me trajeron para acá”. Ya no sabré cómo se dice Eloísa en inglés porque ha venido un policía a buscarme antes de que la llamen y apenas alcanzo a decirle que pida un traductor en su interrogatorio.

Frente a un mostrador, en el que simultáneamente nos despachan a tres viajeros, continúa el kafkiano proceso.

* Cuentista. 
- ¿Cuánto dinero tienes para el viaje?

- Cincuenta mil pesos.

- ¿Estás segura?

- Segura.

- Dame tu tarjeta, voy a llamar a tu banco y si no tienes exactamente cincuenta mil pesos no podrás entrar a los Estados Unidos.

Parece que la verdad es el bien más valioso en este lugar; para encontrarla, cualquier técnica es válida. La traductora roba la identidad de Andrea Rebolledo y con tan sólo los datos del pasaporte, echa abajo el sofisticado protocolo de seguridad de Banamex; la operadora confirma a la apócrifa Andrea que la tarjeta tiene un saldo de ciento cincuenta y cuatro mil pesos.

-¿Por qué mentiste?

-Porque mi hija me dijo que sólo podía usar cincuenta mil pesos en el viaje.

Andrea va a gastar en Estados Unidos mucho más de lo que un estadounidense promedio gasta en Cancún; se va sonriente con sus cincuenta mil pesos, despúes de haber renunciado a su identidad para ganar la pequeña batalla. Mientras tanto, desde uno de los cuartos de interrogatorios llega el sádico eco de una traducción simultánea:

I hope espero that you understand que entiendas that this is que ésta es your last tu última opportunity oportunidad: I can avoid puedo prohibir your admission tu admisión into the United States FOREVER a los Estados Unidos para SIEMPRE. The question is la pregunta es do you want to come back to the United States? ¿Quieres regresar a los Estados Unidos?

La verdadera pregunta que le estaban haciendo a Amador era: “¿cuál es la dirección de tu madre, que vive sin papeles en Atlanta?" Su silencio le costó la revocación de la visa y la deportación a México, 27 horas después de su detención. “¿Por qué tenemos que firmar la declaración en inglés si las preguntas fueron en español?”, me pregunta mientras esperamos nuestro vuelo de vuelta a casa. "A fuerza querían que les dijera que venía a trabajar, y a fuerza querían los datos mi mamá. Me quitaron el teléfono y sacaron los contactos: ¿tú crees que le hablen?" 
"¿Qué dice”, pregunta Rosey que también viene a visitar a su madre, pero desde República Dominicana. Su cara se ilumina cuando entiende que Amador prefirió los cinco años de castigo sin volver a aplicar para una visa antes de revelar la ubicación de su mamá. A Rosey también la acorralaron para declarar que venía a trabajar, y lo lograron. No hay forma de escapar a la versión de la realidad que ellos deciden para ti. Por ser la más joven, le fue confiscada la mayor cantidad de tecnología; nos cuenta que le revisaron su Facebook, su email y sus fotos en el ipad. Ella es quién más tiempo lleva retenida, está a punto de cumplir 24 horas, pero confía en que la subirán al único vuelo que hay a Dominicana. Faltan todavía cuatro horas para que despegue. "¿Por qué ni siquiera hay una tele en este lugar?" Nadie tiene una respuesta para Rosey.

El cuarto donde estamos es del tamaño de la sala-comedor de una casa cualquiera, tiene un gigantesco vidrio por pared; es la segunda sala de retención. Llegué aquí después de cinco horas de espera e interrogatorios entre la caja de supermercado y la pecera gigante. Tenemos que recargar la maleta de mano en el vidrio, en la entrada, antes de pasar al encierro. “¿Vas a leer todo eso?”, me pregunta el policía cuando me ve sacar los cuatro libros y el cuaderno. "Eso déjalo", me dice cuando me ve tomar el arma letal que llevaba conmigo: una pluma. Luego de solicitar autorización a su jefe, me permite entrar con ella. Como por no dejar, añade: “ipero si llevas otra pluma en la bolsa del pantalón!”

También llevo en la misma bolsa la única toalla sanitaria que me queda para pasar el tiempo indefinido que viene por delante. "I need at least two or three like this", digo, y mi kótex revolotea frente a la cara del guardia. Me mira como si fuera la primera vez que le hicieran una petición tan extravagante: resulta evidente que estos policías no están acostumbrados a proporcionar tal tipo de artículos; cuarenta minutos después regresa con una caja de plástico que contiene unas tiras de algodón que parecen el calzón de un luchador de sumo. "It's all we have. Use it." Ni madres. "Ok. I'll ask the police women if they have something for you". Nunca más vuelvo a ver sus ojos desorbitados.

El hambre me dice que ya es el día siguiente. No hay reloj de pared y la luz brillosa no deja adivinar la hora. Pero es una buena luz para leer. 
Wilmer, de Nicaragua; Paco, de Guatemala; Nirú, de la India, el mexicano Amador y yo llevamos libros. Cinco de siete, una proporción de lectores que no se encuentra ni en el metro de París.

Wilmer, Paco y yo somos los más tranquilos, ya habíamos estado antes en Estados Unidos. Nos explicaron que nuestras empresas cometieron un error al enviarnos con visa de turista en vez de visa de trabajo; leo varias veces mi declaración y aún no me explico cómo me acorraló el policía para firmar la versión exacta de los hechos que él quería escuchar: "Subject arrived at the Atlanta POE aboard Delta Flight DL 366 from Mexico an requested admission to continue unlawful 'hands-on' training for an additional three months."

Me preguntó insistente: "Do you understand that your visa is revoked because you participated in unlawful 'hands-on'training on your last visit, and it is your intent to unlawfully train on this visit?"

En ese último "Yes I do" iban mis cuatro horas de espera e interrogatorios, además del día entero entre vuelo y aeropuertos. Entendí entonces que la esquizofrenia americana sólo admite su propia versión de la realidad, por lo cual firmé justo lo que el amable oficial Berwick Babin quería escuchar.

A Amador le habían dicho que le buscarían lugar en el vuelo de las 9 am a México, pero son las 11 y aún no vienen por él. Más temprano se llevaron a Wilmer, a Paco y a un salvadoreño que tuvo la suerte de entrar sólo a dormir en el suelo un par de horas antes de que lo llamaran. Los que seguíamos allí golpeamos con los puños el vidrio blindado para pedir café y té. Se nos une un nuevo grupo, en él vienen Isabel, de Ecuador, y Mariana, de Venezuela. A la misma hora aterriza Michelle Obama en Atlanta.

Una pequeña comitiva gubernamental se asoma a la jaula transparente; sin embargo, ninguno de los tres elegantes políticos se atreve a mirarnos: son sus sonrisas insultantes las que nos inspeccionan. Tan sólo nos separa una pulgada de vidrio blindado y mis puños golpean inútilmente la infranqueable superficie. Improviso una danza, tratando de interceptar sus miradas, pero al parecer los siete detenidos nos desmaterializamos después de 17 horas con apenas un asqueroso arroz en el 
estómago. Necesito que alguien me mire, pero ninguno de los políticos se anima: es como si pudiera transmitirles el ébola con una mirada (y en cierta forma así es): trato de transmitirles una enfermedad que necesita atención inmediata.

Nirú, la mujer que encontré completamente sola en la primera sala de arresto, me preguntó, más que con su inglés imposible, con sus ojos y su bibin en medio de la frente: "Are you from India?" No pudimos hablar más y tampoco fue necesario: con un gesto me confesó que yo me parecía a alguien de la India, pero fuimos separadas en ese momento. Nos volvimos a encontrar a media noche en la segunda sala de encierro; entonces me envolvió en el abrazo que estaba guardando para su hija durante las últimas 35 horas que sumaban su viaje y detención. Nirú es la más grande del grupo y a todos nos duele verla entre nosotros; tiene problemas del corazón y su medicamento se acabó hace varias horas. Necesita otra dosis urgentemente. Queremos un traductor y medicina para Nirú; a cambio sólo obtenemos sonrisas artificiales que se regocijan en su propia versión de la realidad. La comitiva política contempla sin ojos la confortable "sala de detención" que desde afuera se mira. Adentro, todos sabemos que estamos en la cárcel.

“'Susan Patinio!” El maravilloso grito indica que mi avión está listo, que regreso a México. Me despido con pesar de estos compañeros, en quienes no he dejado de pensar, y les cedo mi bien más preciado: un tubo de pasta de dientes.

- Why are you here?

- ¡No empiecen otra vez con sus preguntas, déjenme ir!

- You don't get it, you should not be here. You're free.

Sé que en México mi liberación habría costado mucho más tiempo y algún esfuerzo de mi familia y de los amigos pero, sobre todo, dinero; sin embargo, en el sueño americano cualquier cosa es posible: una simple llamada de mi compañía creó una realidad aún más convincente que aquella en la yo participaba en una actividad ilegal de forma sistemática.

Ahora mi visa tiene una leyenda en diagonal que dice CANCELED ATL 9/07/14 22CFR41,122(a)3 y abajito, con pluma bic, le pusieron IN ERROR. 
Dear U.S Department of Homeland Security: ¿es que sus autoridades también anotan -con pluma bic- una leyenda que dice IN ERROR sobre el expediente de quien no debía ser ejecutado en la silla eléctrica? Les informo que estoy aún en su país, sin visa y que nada ha cambiado en mis unlawful activities. ¡Vengan por mí! ¿Cuál es mi realidad ahora, según ustedes? Yo sólo admito aquella donde los zapatos blancos de Eloísa puedan pasearse libremente por todos los caminos posibles. 